\title{
Development of Autonomous VTOL UAV for Wide Area Surveillance
}

\author{
Daeil Jo, Yongjin Kwon* \\ Department of Industrial Engineering, College of Engineering, Ajou University, Suwon, South Korea \\ Email: ^yk73@ajou.ac.kr
}

How to cite this paper: Jo, D. and Kwon, Y. (2019) Development of Autonomous VTOL UAV for Wide Area Surveillance. World Journal of Engineering and Technology, 7, 227-239. https://doi.org/10.4236/wjet.2019.71015

Received: January 16, 2019

Accepted: February 16, 2019

Published: February 19, 2019

Copyright (c) 2019 by author(s) and Scientific Research Publishing Inc. This work is licensed under the Creative Commons Attribution International License (CC BY 4.0).

http://creativecommons.org/licenses/by/4.0/ (c) (i) Open Access

\begin{abstract}
The drone was developed with the use of unmanned aircraft systems in the initial military sector based on the combination of aerospace technology and information and communication technologies in a variety of usability, including the civilian sectors. Developed for the field of reconnaissance, it is used in both civilian and police sectors as traffic monitoring and high altitude reconnaissance missions. It is used in broadcasting and surveillance, while continuously expanding into the areas of courier delivery and rescue missions. Based on the convergence of aviation technology such as various SW, sensor and flight control to utilize unmanned system and information communication technology, commercialization of related technology is being developed as a very diverse route. In this paper, we propose and manufacture of a VTOL UAV. Design process referred to the VTOL development process that has been devised by us, and actual building of a UAV also applied the same VTOL development concept. In order to understand the aerodynamic characteristics of the aircraft, we have applied the aerodynamic design theory and used the CAE method that can replace the actual wind tunnel test. We tested the selection method and criteria for the internal modules that make up the $\mathrm{UAV}$, and we were able to assemble the product. FW coding of flight control computer was conducted for VTOL control. In addition, we developed a LTE communication module for the long distance flight, and carried out flight experiments with GCS to observe and respond to the flight situation from the ground. Flight test results showed that stable transition flight was possible with broadband. We could see that the actual performance results were met, compared to our development target values.
\end{abstract}

\section{Keywords}

UAV, VTOL, Fixed Wing, Drone, Multi-Copter, Rotary Wing, Aircraft Design, Transition Flight 


\section{Introduction}

With the recent surge of interest in UAVs (unmanned aerial vehicles), there has been an increasing trend in utilization for many industrial sectors, including agricultural control, forest and coastal surveillance, search for victims, broadcasting and photography. The most widely used type of commercial UAV is a multi-copter type UAV, which can take off and land vertically. However, it can't generate a wing-lift due to the characteristics of propellant types, which shortens the flight time. On the other hand, the fixed-wing type UAV has an advantage of longer flight time and higher speed, but it is difficult to secure a wide space for safe landing. This has been a great limitation in utilization. This study aims to develop a VTOL (vertical takeoff and landing) UAV, utilizing the advantages of both multi-copter type and fixed-wing type UAV [1] [2] [3].

\section{The VTOL Development Process}

The overall development process of the vertical takeoff and landing VTOL UAV performed in this study is shown in Figure 1. This is based on our genuine effort to establish a systematic and sound UAV development, which has been mainly based on each developer.

\subsection{Body Frame Design}

The airframe design is an important part of the UAV development designed to reduce the air resistance. Compared to the quad-X type design (a typical multi-copter design), it is aesthetically and aerodynamically superior. Shown in Figure 2, its design ensures a large mounting space at the center of the fuselage to load various mission equipment and cargo [4].

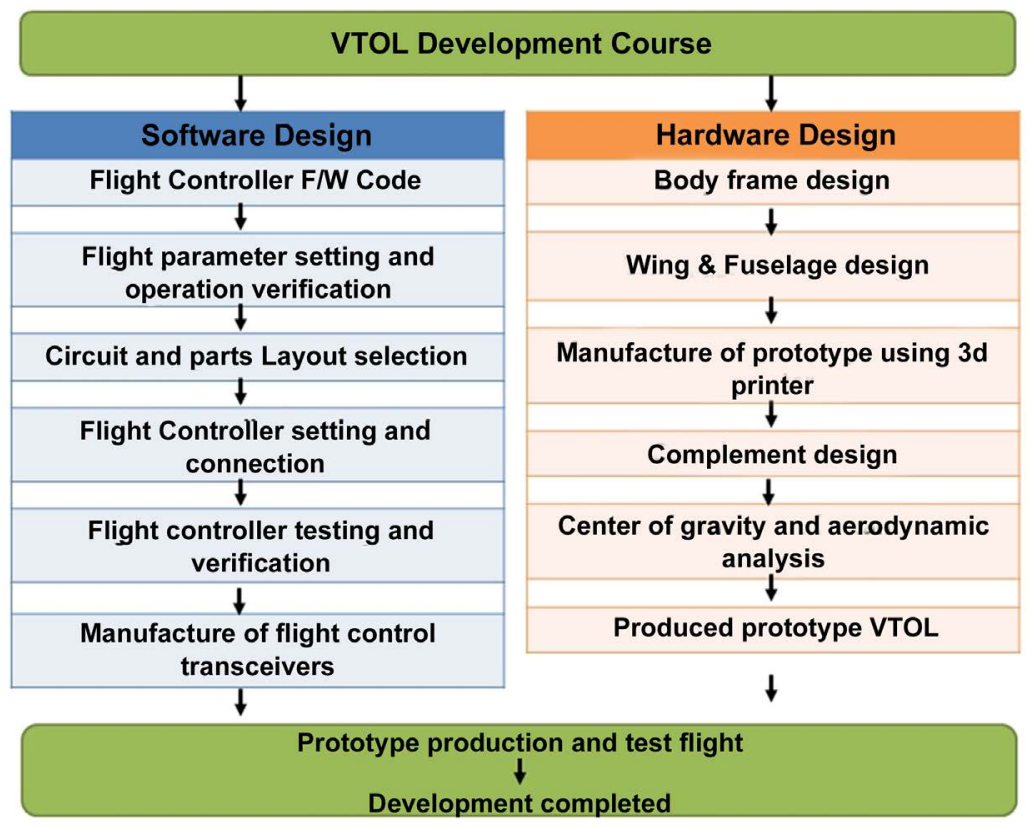

Figure 1. VTOL development process, established by the authors' effort. 


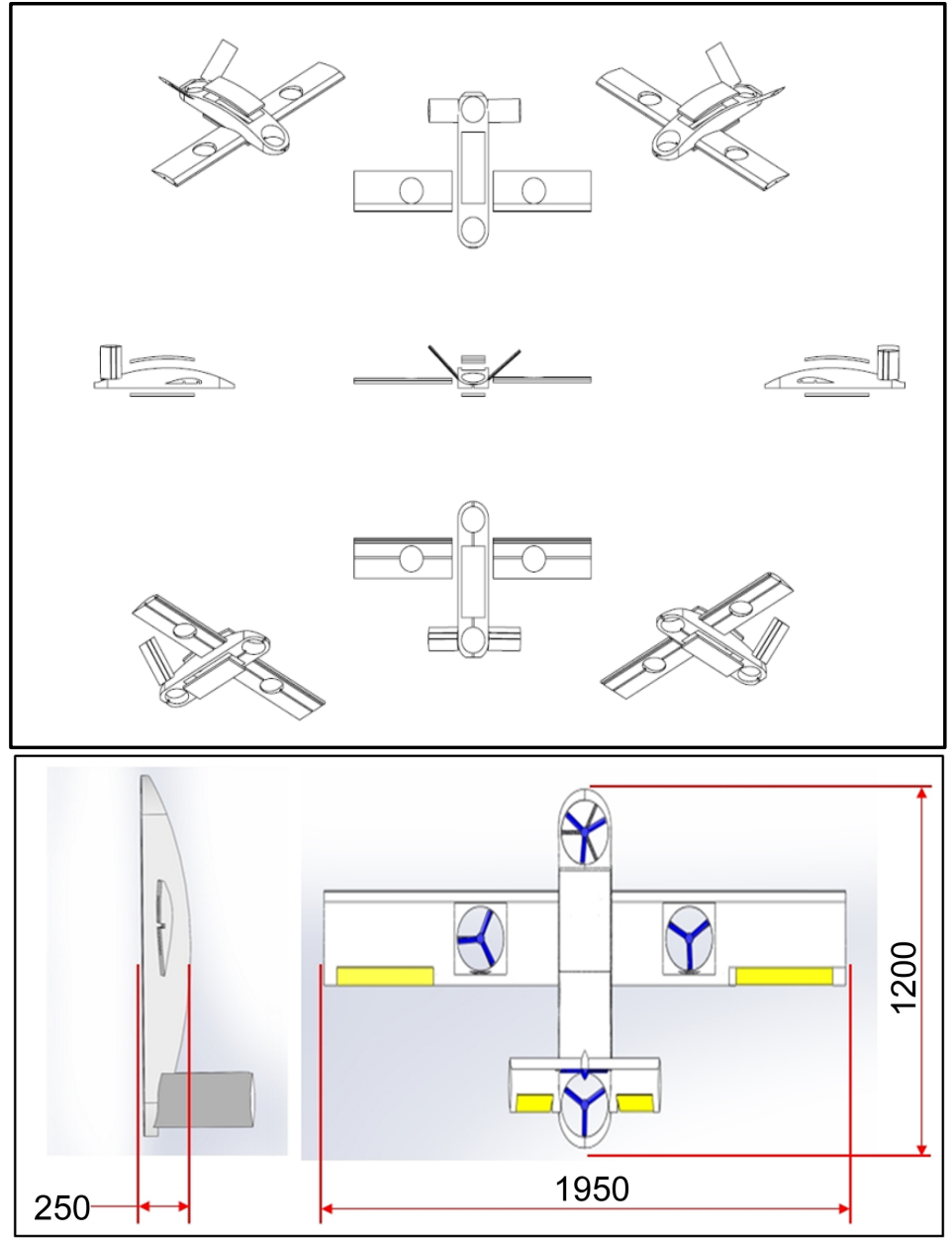

Figure 2. Body frame design layout.

\subsection{Wing \& Fuselage Design}

Wing is an important part of determining the performance of UAV. The wing can be designed in various ways, such as low-wing, mid-wing and high-wing, which is mainly dependent on the desired flight characteristics. In the case of the lower wing, it has the merit that it can increase the maneuverability. In the case of the central wing, the balance of frame is said to be the best. Using the CAE (computer-aided engineering) software, the design of the wing shape was analyzed. The flight dynamic characteristics such as air resistance, lift, curvature analysis, airfoil, and air flow, are shown in Figure 3. The experimental conditions are boundary conditions when flying at $0^{\circ} \mathrm{C}$ and $15 \mathrm{~m} / \mathrm{s}$. In the previous study, we designed the airfoil for the VTOL design as shown in Figure 4, and developed the airfoil which can achieve the efficiency at a low speed, considering that the maximum speed is $80 \mathrm{~km} / \mathrm{h}$ and the cruising speed is $60 \mathrm{~km} / \mathrm{h} \mathrm{[5]} \mathrm{[6]}$ [7].

\subsection{Selection of Motor Thrust}

The output is determined by the rotational speed of the motor and the propeller. 


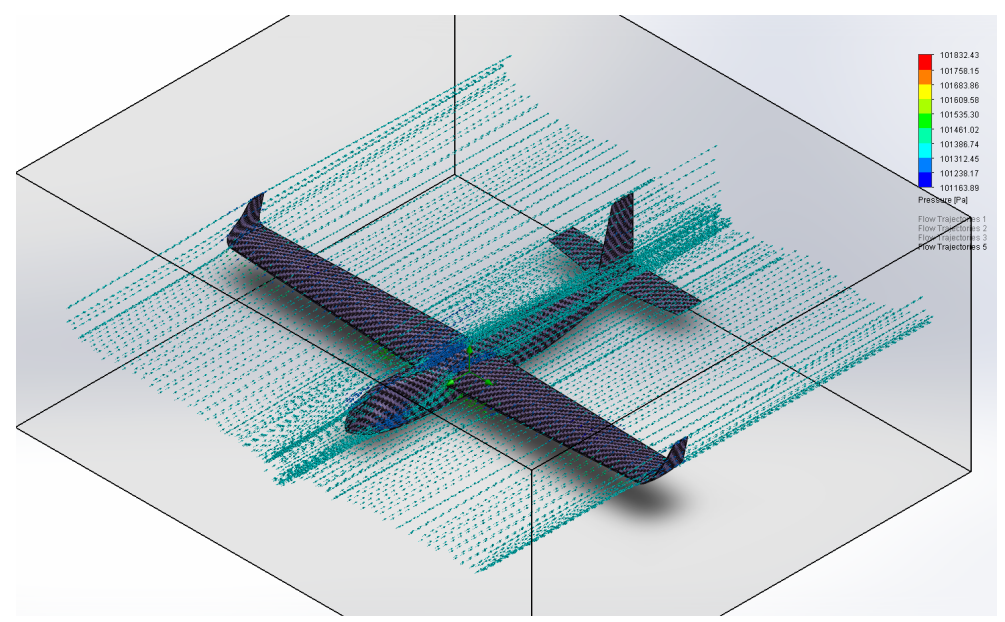

Figure 3. CAE simulation Analysis 1.

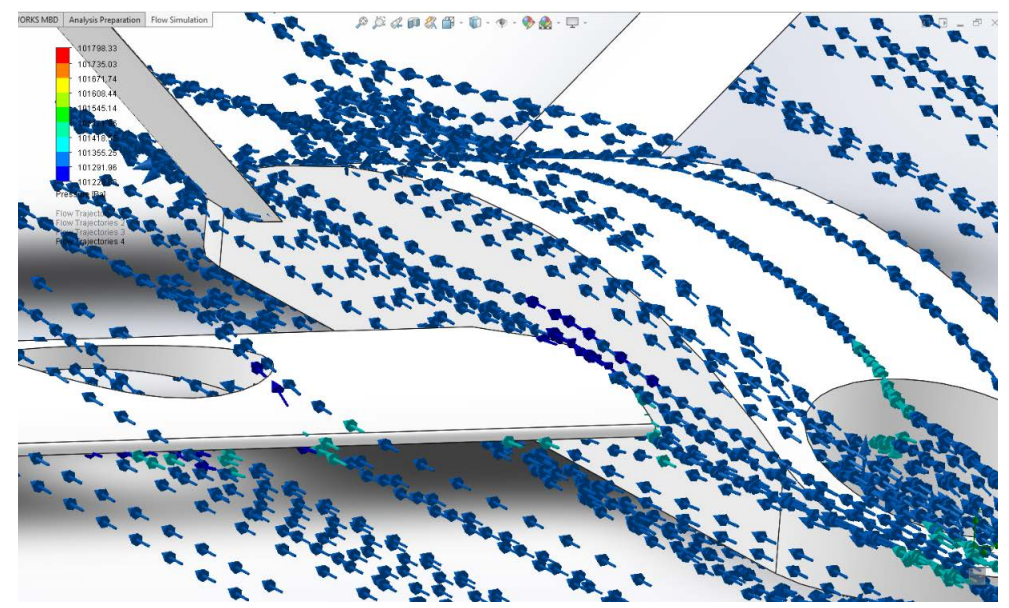

Figure 4. CAE simulation Analysis 2.

The thrust determination equation is shown in Equation (1). Also, the equation to determine the propeller for generating the thrust after determining the required thrust is shown in Equation (2) [8].

$$
\begin{gathered}
\text { Power }=\text { Prop Const } \times \mathrm{rpm}^{\text {Power factor }} \\
T=\frac{\pi}{4} D^{2} \rho v \Delta v
\end{gathered}
$$

T: thrust $[\mathrm{N}]$.

$D$ : propeller diameter $[\mathrm{m}]$.

$v$. velocity of air the propeller $[\mathrm{m} / \mathrm{s}]$.

$\Delta v$. velocity of air the accelerated by propeller $[\mathrm{m} / \mathrm{s}]$.

$\rho$. density of air $\left[1.225 \mathrm{~kg} / \mathrm{m}^{3}\right]$.

\subsection{Selection of Propellers}

The greater the number XX and the larger the number YY, the higher lift can be achieved. The propeller should be large with a high pitch. But, as the weight of the propeller increases, the battery consumption increases accordingly. This 
leads to the decrease of the flight time. Therefore, it is necessary to select the proper propeller, according to the size of the airframe and the specification of the motor. Based on the motor selected in this way, the propeller is selected using Equation (3) from the source of known reference [9] (Figure 5).

$$
\mathrm{rpm}_{\text {ideal }}=\left(\frac{2}{\pi}\right)^{\frac{1}{2 \omega}}\left(\frac{g^{\frac{3}{2}} m^{\frac{3}{2}}}{\alpha D \sqrt{\rho}}\right)^{1 / \omega}
$$

$$
\begin{aligned}
& \omega=\text { Power Factor from Aircraft. } \\
& \alpha=\text { Power Coefficient from Aircraft. } \\
& D=\text { Diameter }[\mathrm{m}] . \\
& \rho=\text { Air Density }\left[1.225 \mathrm{~kg} / \mathrm{m}^{3}\right] . \\
& m=\text { Mass }[\mathrm{kg}] . \\
& g=\text { Gravity }\left[9.8 \mathrm{~m} / \mathrm{s}^{3}\right] .
\end{aligned}
$$

\subsection{Selection of ESC \& Power Pack}

The ESC (electronic speed control) is a device that can control the direction and speed of the drone motors. It can supply the proper voltage, depending on the motor or battery and is designed to handle the maximum current used by the motor. Figure 6 shows the selected ESC of $40 \mathrm{~A}$.

The battery is directly related to the flight time. Equation (4) represents the flight time, according to the capacity and the consumption current of the battery.

$$
\text { Flight time }=\text { Battery capacity/amp }
$$

$$
\text { Flight time }=2000 \mathrm{mAh} * \frac{60 \mathrm{~min}}{(\text { hour })} * \frac{1}{(8 \mathrm{~A})} * \frac{A}{(10000 \mathrm{~mA})}=15 \mathrm{~min}
$$

The battery in this study was selected as 6 Cell, $24 \mathrm{~V}, 10,000 \mathrm{mAh}$ type, considering flight time and thrust. Here, the " $\mathrm{mAh}$ " indicates the capacity of the battery. For example, an indication of 100,000 mAh means that you can use 1 hour when you draw 10,000 $\mathrm{mA}$. The "V" indicates the voltage. One must use a battery with the proper voltage to stabilize the current to the drive motors.

The "Wh" shows how much power the battery has. This value can be calculated

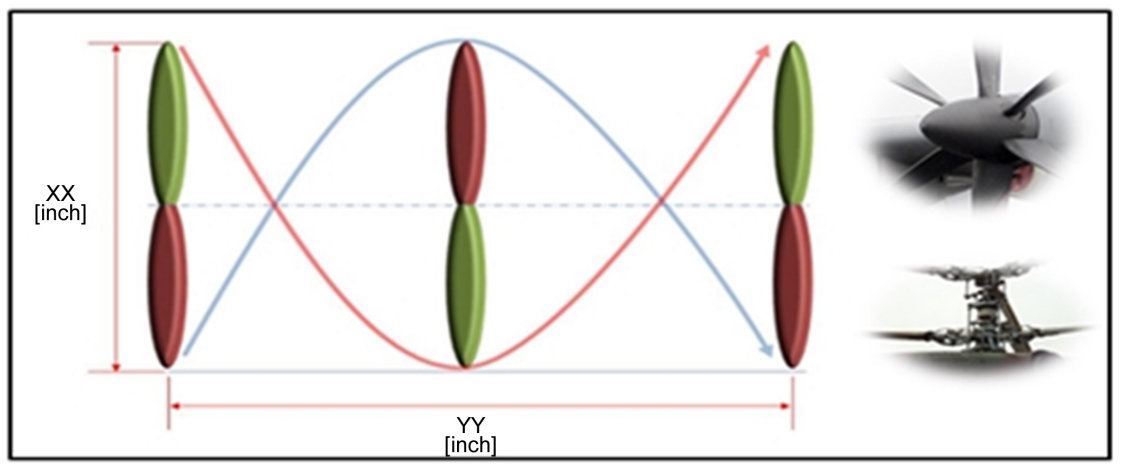

Figure 5. Propeller selection XX \& YY. 


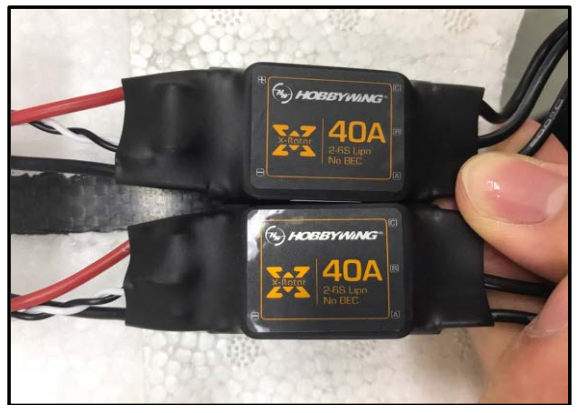

Figure 6. Selection of 40A ESC.

by multiplying the capacity $\mathrm{mAh}$ with the voltage $\mathrm{V}$. The " $\mathrm{C}$ " indicates the discharge rate. In this study, we used the Motocalc SW, as shown in Figure 7. This software predicts the flight performance according to the parameters of the motor and propeller. The propeller length was 14 inches and the battery was HBZ-B $520022.2 \mathrm{~V}$. The motor was selected as Quantum $400 \mathrm{kv}$. As a result, it was estimated that the thrust was about $12 \mathrm{~kg}$ or more. It is designed to be more than 3 times the weight of the airframe and enough to lift the airframe vertically with a $3 \mathrm{Kg}$ load. Table 1 shows the VTOL specifications produced by the study [10] [11] [12].

\section{VTOL Assembly}

\subsection{Airframe Manufacturing}

The designed UAV parts are produced by using a 3D printer and the UAV is assembled as shown in Figure 8. The 3D printed parts were mainly used to test and evaluate our initial design.

The final frame was produced after identified problems were solved, based on the data obtained from the prototype production. Figure 9 and Figure 10 show the process of fabricating and assembling the final airframe [13] [14].

\subsection{Flight Control Computer FW Coding for VTOL Control}

The software setting is the core of FCC (flight control computer) coding. The FCC has built in components such as accelerometer, gyro, geomagnetic, barometer, GPS (global positioning system) and CPU (central processing unit), to maintain the stabilized flight by sensing the equilibrium state of VTOL. The geomagnetic system measures the movement direction of the airframe, while the barometer measures the altitude of the VTOL. The GPS tracks the flight routes of the UAV and performs the mission profile. In this study, FW (firmware) is coded using the Pixhawk controller, which is the most used FCC. The Pixhawk is an open source, and FW coding was developed as shown in Figure 11, using the C-language [15].

\subsection{Development of LTE Communication Module}

In a line-of-sight flight, it is easy to manipulate the UAV because it can be adjusted 
Table 1. VTOL specifications.

\begin{tabular}{cc}
\hline Contents & Specifications \\
\hline Length & $1200 \mathrm{~mm}$ \\
Wing Span & $1950 \mathrm{~mm}$ \\
Empty Weight & $3.9 \mathrm{Kg}$ \\
Horizontal Thrust & $3.0 \mathrm{~kg}$ \\
Vertical Thrust & $12.0 \mathrm{~kg}$ \\
Power Pack & 6 Cell, 24 V, 10,000 mAh \\
\hline
\end{tabular}

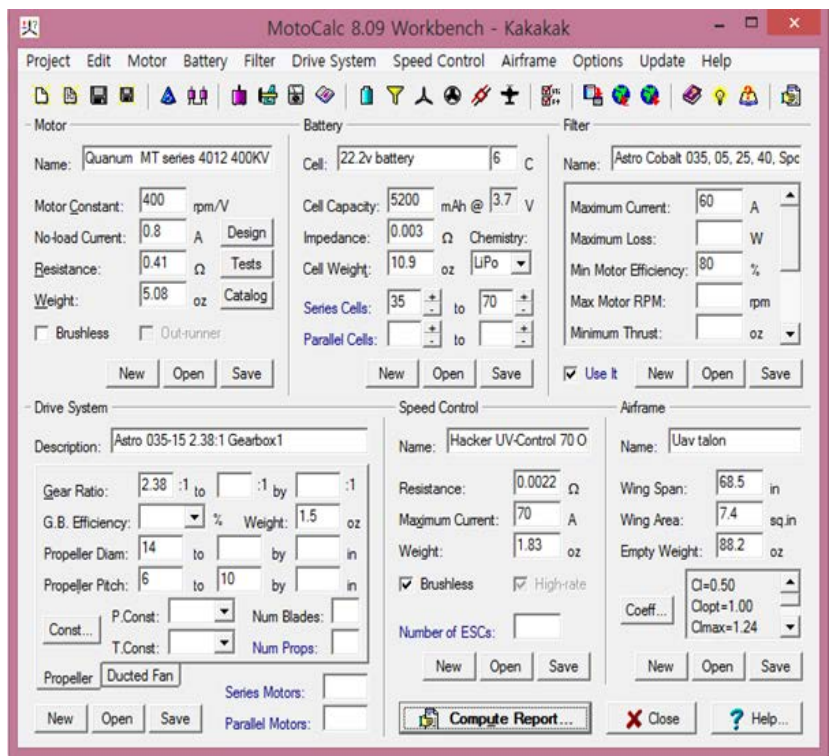

Figure 7. Thrust calculation using Motocalc S/W.

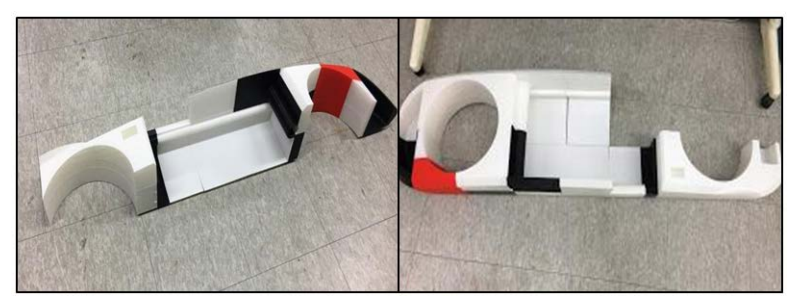

Figure 8. Fuselage sections of the 3D printed parts.

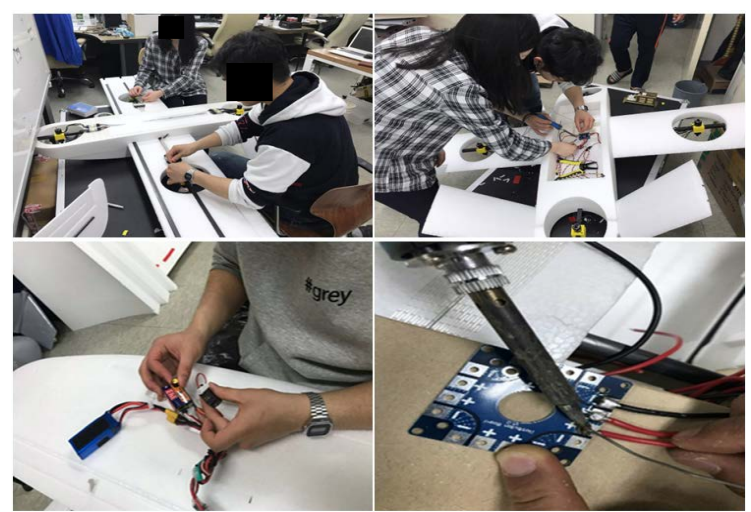

Figure 9. Parts assembly and various wiring work. 


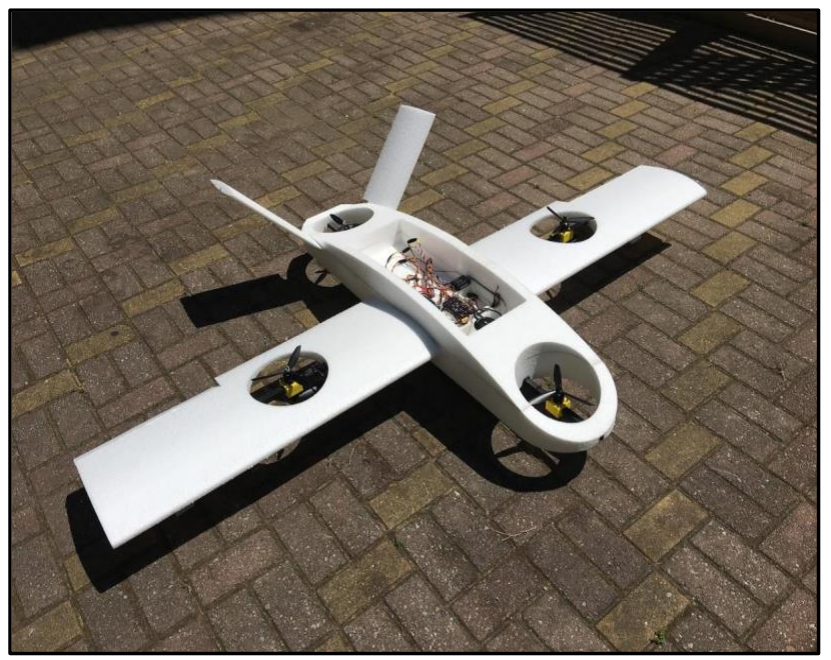

Figure 10. Completed VTOL UAV.

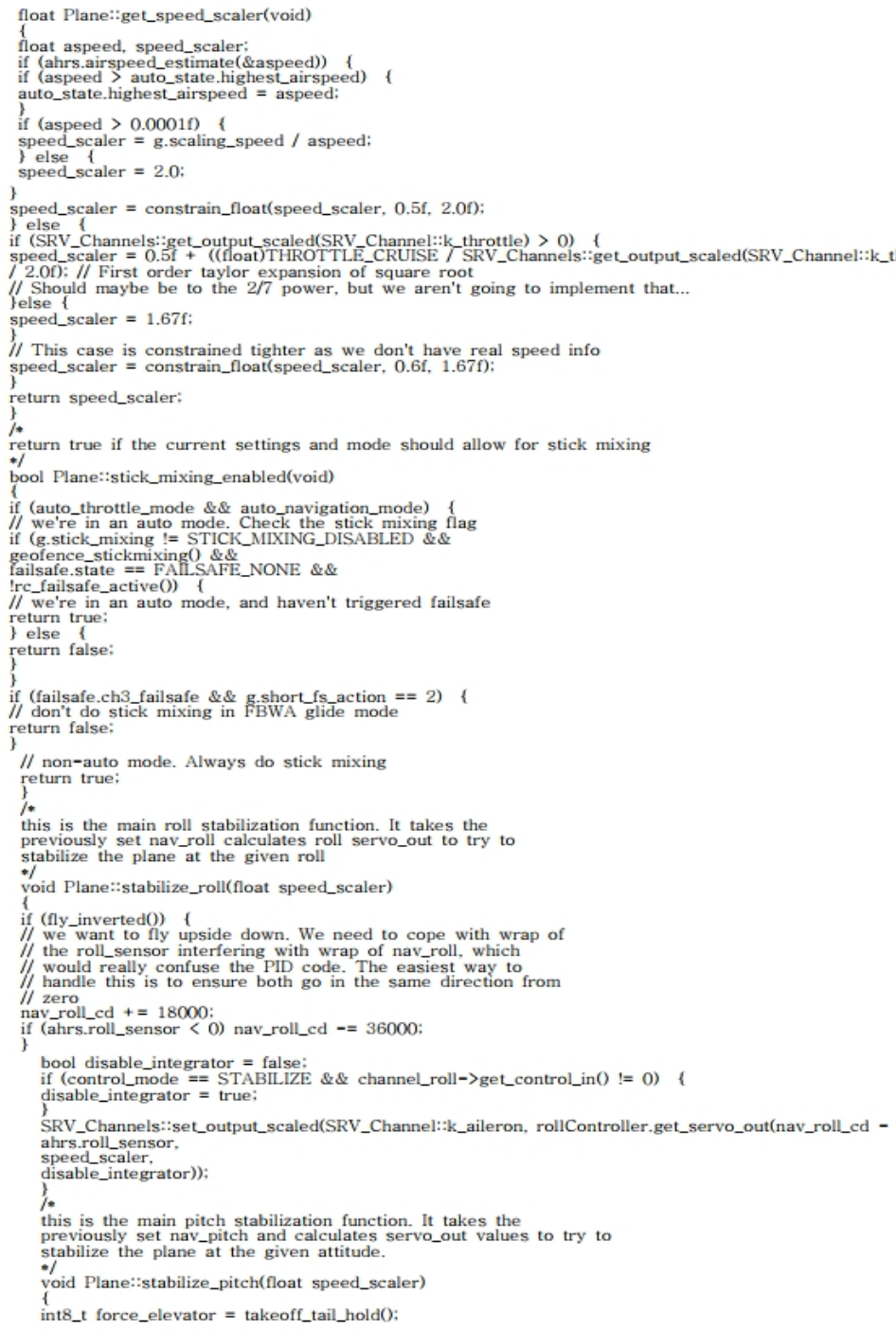

Figure 11. C-based navigation system coding. 
by looking at the airframe. The UAV can be controlled in real-time, using 5.8 Ghz of for analog video transfer and $2.4 \mathrm{Ghz}$ of frequency for the manipulator. When flying a long distance, it can be controlled through the LTE (long-term evolution) communication by using the automatic flight function. By developing a library to connect FCC and LTE modem, the UAV pilot can remotely check the flight images and UAV status, while controlling the UAV beyond the line-of-sight. As shown in Figure 12, the LTE modem developed in this study can be easily added in the future.

\subsection{Ground Control Station Design and Production}

For the remote control of UAV, the GCS (ground control station) is developed. The GUI-based (graphical user interface-based) environment and a user-friendly user interface have been developed, so that the flight status can be observed and confirmed on a map screen. The UAV flight control is equipped with both automatic flight and manual flight. As shown in Figure 13, the touch-screen displays the preprogrammed flight path. The control button layout is configured to increase the usability [16] [17] [18] [19].

\section{VTOL Flight Experiments}

In this section, we analyzed the flight characteristics of the developed VTOL. Through numerous trials and errors, we have optimally set up the flight parameters

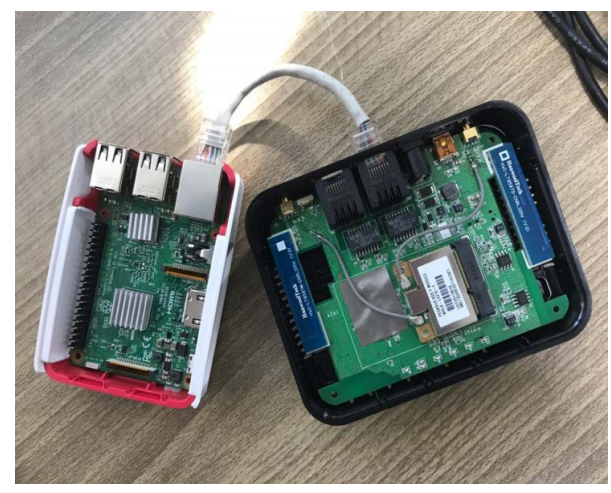

Figure 12. Self-developed LTE modem.

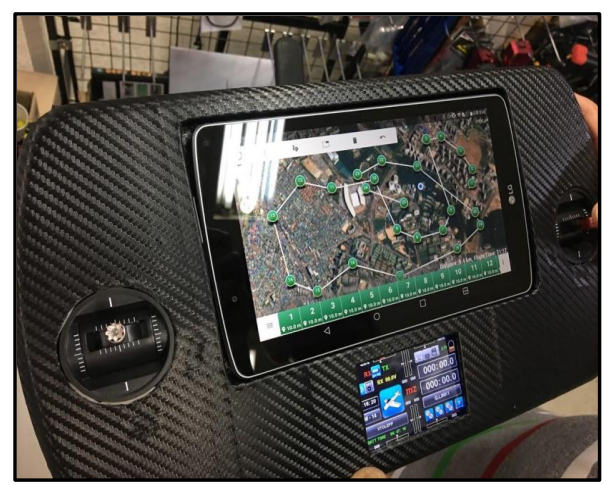

Figure 13. GCS for both automatic and manual flight control. 
that can effectively control the VTOL. Figures $14-17$ show a part of the test flight process.

Table 2 compares the target performance parameters and the actual performance data of the VTOL developed in this study. All parameters either meet or exceed the target values.

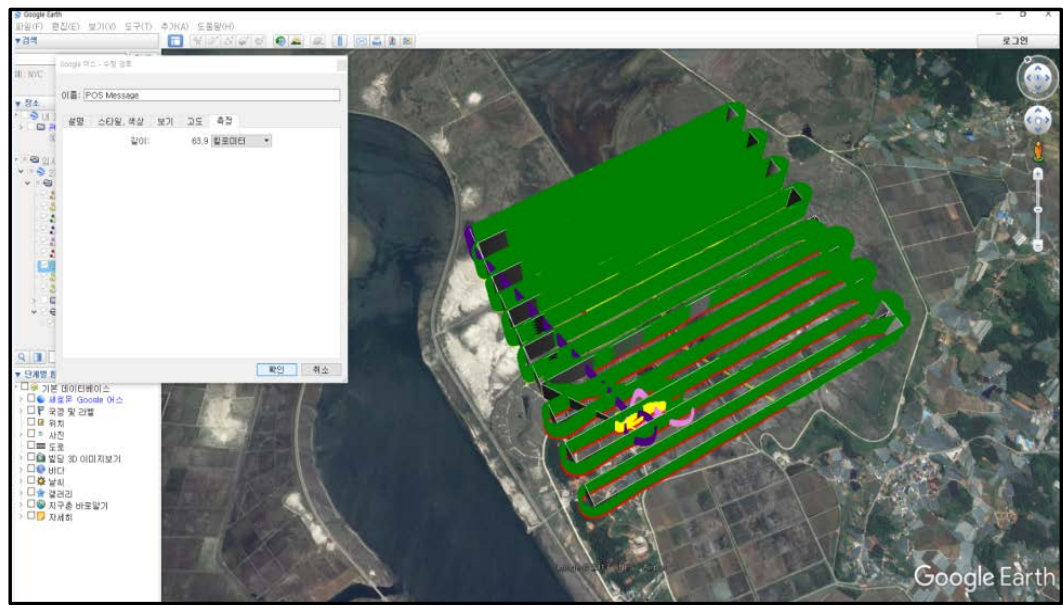

Figure 14. Preparatory work for flight experiments.
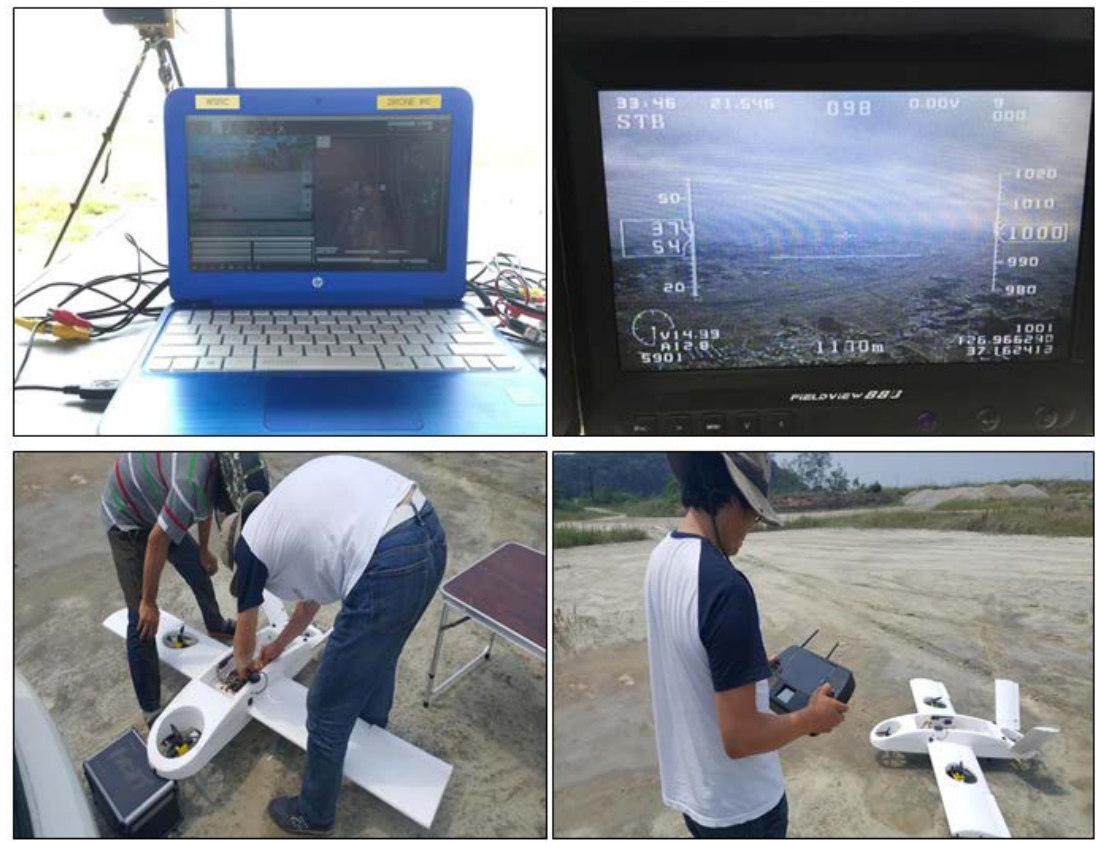

Figure 15. Automatic route flight.

Table 2. Comparison of the development goals with the actual performance data.

\begin{tabular}{cccccc}
\hline Spec & Unit & Target & Before Study & After Study & Goal \\
\hline Flight Time & $\min$ & $\geq 60$ & 20 & 65.9 & Satisfied \\
Fly & $\mathrm{Km}$ & $\geq \mathrm{R} 20$ & 2 & 30 & Satisfied \\
Hovering Tolerance & $\mathrm{m}$ & $\leq 0.5$ & 1.5 & 0.5 less & Satisfied
\end{tabular}




\section{Continued}

\begin{tabular}{cccccc}
\hline Vertical Ascent Rate & $\mathrm{m} / \mathrm{s}$ & $\geq 3.0$ & 2 & 8 & Satisfied \\
Vertical Descent Speed & $\mathrm{m} / \mathrm{s}$ & $\geq 4.0$ & 1 & 50 & Satisfied \\
Horizontal Flight Speed & $\mathrm{Km} / \mathrm{h}$ & $\geq 80 \mathrm{Km} / \mathrm{h}$ & 45 & 108 & Satisfied \\
Wireless Distance & $\mathrm{Km}$ & & LTE Networks & & Satisfied \\
Bank Angle & Angle & \pm 45 & 20 & $+71,-65$ & Satisfied \\
Pitch Angle & Angle & \pm 25 & 20 & $+34,-25$ & Satisfied \\
Maximum Load Weight & $\mathrm{Kg}$ & $\geq 3.0$ & 1 & 3 more & Satisfied \\
\hline
\end{tabular}

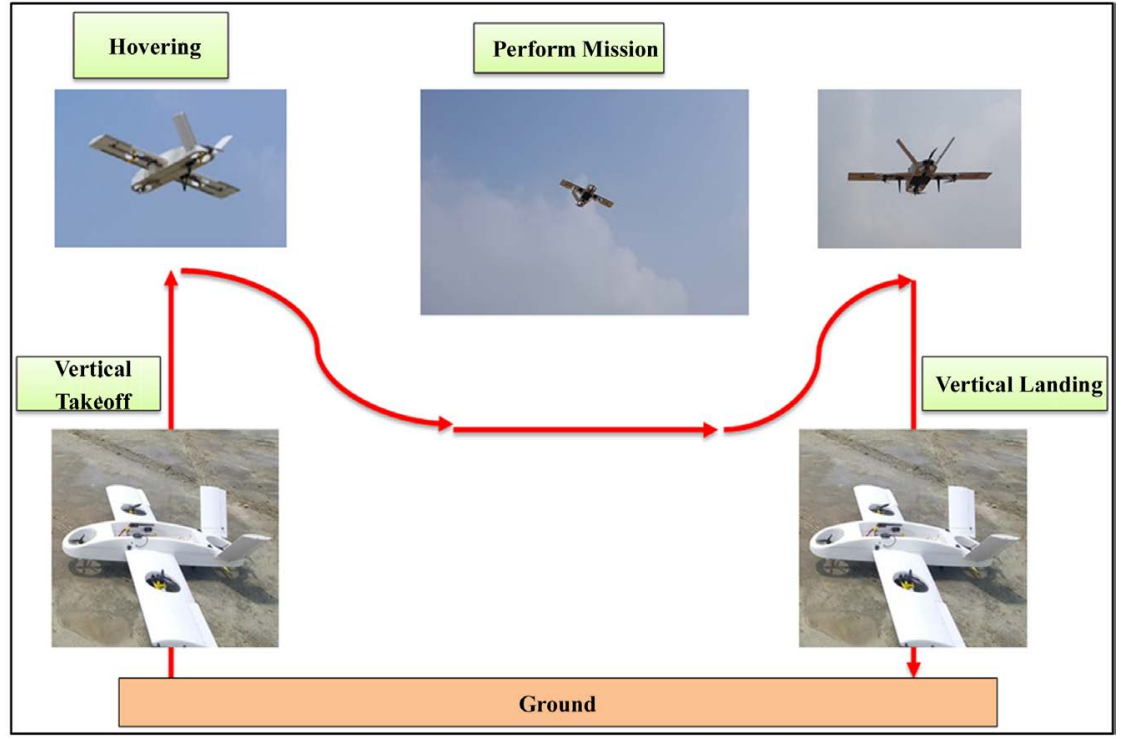

Figure 16. Profile of the VTOL flight experiments.

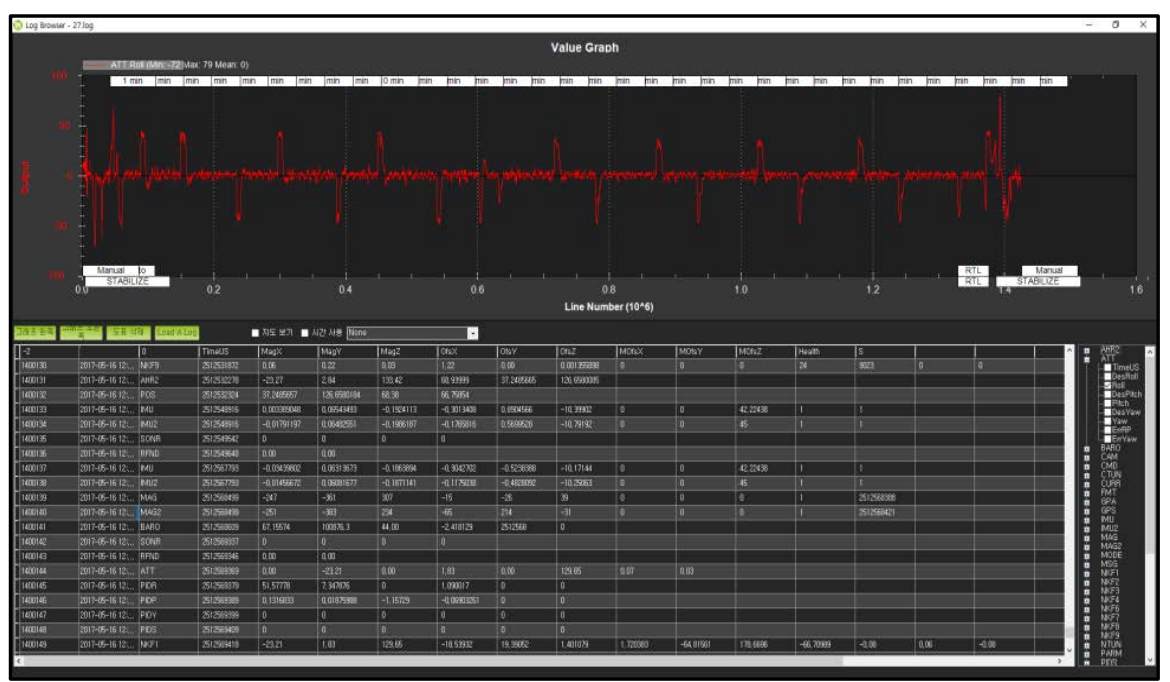

Figure 17. Log data extracted from the flight experiments.

\section{Conclusion}

In this paper, we proposed the VTOL UAV and studded the design and manu- 
facturing process of the UAV. We developed the VTOL development process and actually followed the process to design and build the UAV. The process is systematic and not ad-hoc based. The developed process has been successfully applied to the new VTOL design and manufacture. In order to understand the aerodynamic characteristics of the VTOL, we applied both the aerodynamic design theory and the CAE that can replace the actual wind tunnel test. We tested the selection method and criteria for the internal modules that make up the UAV, and we were able to assemble the product. Firmware coding of the flight control computer was conducted as well. In addition, we developed a LTE communication module for long distance flight, and carried out flight experiments with the GCS to observe and monitor the flight status from the ground. Flight tests showed that a stable transition flight was possible with our method and we could see that the actual performance results were met compared to the development target.

\section{Acknowledgements}

Following are results of a study on the "Leaders in Industry-University Cooperation+" Project, supported by the Ministry of Education and National Research Foundation of Korea.

\section{Conflicts of Interest}

The authors declare no conflicts of interest regarding the publication of this paper.

\section{References}

[1] Jo, D. and Kwon, Y. (2017) Analysis of VTOL UAV Propellant Technology. Journal of Computer and Communications, 5, 76-82. https://doi.org/10.4236/jcc.2017.57008

[2] Jo, D. and Kwon, Y. (2017) Development of Rescue Material Transport UAV. World Journal of Engineering and Technology, 5, 720-729. https://doi.org/10.4236/wjet.2017.54060

[3] Kim, K.B. (2013) Design and Verification of Multi-Rotor Based Unmanned Aerial Vehicle System. Ph.D. Thesis, Department of Mechanical Engineering, Konkuk University, South Korea.

[4] Lee, C.J. (2017) Aircraft Structural Design Practice. Good Land-Company, McMinnville.

[5] kevadiya, M. (2013) CFD Analysis of Pressure Coefficient for NACA 4412. International Journal of Engineering Trends and Technology (IJETT), 4, 2041-2043.

[6] Yun, S.J. (2010) Aerodynamics. Saintian-Company, Pajoo.

[7] SOLIDWORKS 2017 (2017) Structural Analysis \& Flow Simulation.

[8] Green, W.E. and Oh, P.Y. (2006) Autonomous Hovering of a Fixed-Wing Micro Air Vehicle. IEEE International Conference of Automation (ICRA), Orlando, 15-19 May 2006, 2164-2169.

[9] https://quadcopterproject.wordpress.com

[10] De la Torre, G.G., Ramallo, M.A. and Cervantes, E.G. (2016) Workload Perception 
in Drone Flight Training Simulators. Computers in Human Behavior, 64, 449-454.

[11] Liu, Z. and Li, H. (2016) Research on Visual Objective Test Method of High-Level Flight Simulator. Journal of System Simulation, 7, 1609-1614.

[12] Luan, L.-N. (2013) Augmenting Low-Fidelity Flight Simulation Training Devices via Amplified Head Rotations. Loughborough University, Loughborough.

[13] Lee, S. and Lim, K. (2008) PCB Design Guide Book. Sehwa Publishing Co., South Korea.

[14] Kang, M. and Shin, K. (2011) Electronic Circuit. Hanbit Media, Seoul.

[15] Yoon, H. (2015) Mitigation Settings and Their Execution Scenario in Drone Firmware. International Research Journal of Computer Science (IRJCS), 2, 7-11.

[16] Lee, E., Kim, S. and Kwon, Y. (2016) Analysis of Interface and Screen for Ground Control System. Journal of Computer and Communications, 4, 61-66. https://doi.org/10.4236/jcc.2016.45009

[17] Kwon, Y., Heo, J., Jeong, S., Yu, S. and Kim, S. (2016) Analysis of Design Directions for Ground Control Station (GCS). Journal of Computer and Communications, 4, 1-7. https://doi.org/10.4236/jcc.2016.415001

[18] Yu, S., Heo, J., Jeong, S. and Kwon, Y. (2016) Technical Analysis of VTOL UAV. Journal of Computer and Communications, 4, 92-97. https://doi.org/10.4236/jcc.2016.415008

[19] Hong, J., Baek, S., Jung, H., Kim, S. and Kwon, Y. (2015) Usability Analysis of Touch Screen for Ground Operators. Journal of Computer and Communications, 3, 133-139. https://doi.org/10.4236/jcc.2015.311021 